\title{
Advances in Local Anaesthesia: A Paediatric overview
}

Ganapathy Sriram

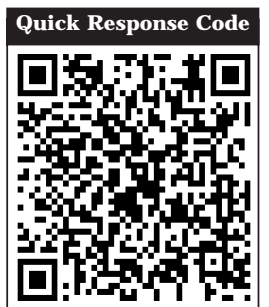

doi : 10.5866/2014.631605

${ }^{1}$ Assistant Professor,

Deptartment of Oral and Maxillofacial Surgery,

Government Dental College and Hospital,

Aurangabad, India

\section{Article Info:}

Received: April 11, 2014

Review Completed: May 10, 2014

Accepted: J une 13, 2014

Available Online: October, 2014 (www.nacd.in)

(C) NAD, 2014 - All rights reserved

\section{Email for correspondence:}

dr.ganapathysriram@gmail.com

\begin{abstract}
:
Administering a safe and effective local anaesthesia to a child is a challenging task but also an essential skill for a successful practitioner. Advancements in local anaesthesia have led to newer agents, newer equipments and also modification in techniques. This article is an attempt to review the most recent advances in local anaesthesia pertaining to the practice of paediatric dentistry.
\end{abstract}

Key words: Local Anaesthesia, Advances

article discusses the most recent development in local anaesthesia relevant to the practice of paediatric dentistry.

\section{Lidocaine Patch:}

It is a transoral lidocaine delivery system, approved by FDA for clinical use in 1996. DentiPatch is one such product released by Noven Pharmaceuticals. It is an adhesive containing $46.1 \mathrm{mg}$ of lidocaine per each $2 \mathrm{~cm}^{2}$. Non-active ingredients include: karaya gum, glycerin, dipropylene glycol, lecithin, propylene glycol, aspartame, spearmint flavour, polyester film laminate and polyester-rayon fabric. Each unit is sealed in a paper polyethylene-foil pouch. The lidocaine is absorbed by the mucosa and onset of anaesthesia is within 2.5 minutes of application. The patch is to be left in place for 15 minutes and the anaesthetic effect can last up to 30 minutes after would be of great help to the practitioners. This

\section{Indian Journal of Dental Advancements Journal homepage: www. nacd. in}


removal. Blood levels of lidocaine following application are less than $0.1 \mathrm{mg} / \mathrm{ml}$ and the risk of systemic toxicity is negligible. It is indicated for use when mild topical anaesthesia is desired for superficial dental procedures or prior to local anaesthetic injection. Disadvantages of lidocaine patch includes its high cost and poor adherence of the patch to the oral mucosa. Lidocaine patch is a good alternative to conventional topical anaesthetic agents for paediatric patients. However, the effectiveness of lidocaine patch to topical anaesthetic agents is questionable and under investigation. A study comparing the use of mucosal adhesive patch and topical anaesthetic solution(Benzocaine) showed no significant difference between the two products. ${ }^{1}$

\section{Vibratory Devices:}

Gate control theory is considered to be one of most accepted theory of pain. It was introduced by Dr. Ronald Melzack and Dr. Patrick Wall in 1965. This theory conceptualizes a 'sensory gate' present in the dorsal horn of the spinal cord that controls/ modulates the perception of pain by the central nervous system. In the recent years, few innovative products were developed taking into consideration this gate control theory of pain. These products work on the principle of masking the pain rather than eliminating the cause of pain.

\section{(i) Vibraject:}

Vibraject was patented by a oral surgeon Dr. Norman Pokran and developed by dental product inventor Ron Cross. It is a small battery driven motor that vibrates at 10,000 cycles per minute which can be attached to a syringe with an autoclavable clip. During injection 'pain signals caused by penetration of the needle and 'pressure or vibratory' signals caused by the vibraject are combined. In such circumstances the 'pain signal' transmitted by the small nerve fibres is inhibited and 'vibratory' signals transmitted by large nerve fibres are perceived by the central nervous system. Thus the patient doesn't feel pain because the 'pain' signal is masked by the vibratory signal. Vibraject is simple to use and attaches to any conventional syringe. Syringe MicroVibrator is a another device similar to Vibraject has been introduced very recently. ${ }^{2}$

\section{(ii) Dental Vibe:}

Dental Vibe was invented by Dr. Steven Goldberg, a Florida based dentist. It is a cordless, rechargeable hand held device that del ivers soothing pulsed, percussive micro-oscillations to the site where an injection is being administered, which the manufacturers have termed it "Vibrapulse" technology. These pulsations also help in dissipitating the bolus of injected local anaesthesia more efficiently through the tissues resulting in a more profound anaesthetic action. An audible distraction, such as a buzzing sound at a range of 70$75 \mathrm{db}$ has been added to the dental vibe which acts as a distraction stimulus for concentration during injection. Thetips of the dental vibeare designed with pressure sensing feature that enables the device to shut off when excessive pressure is applied.

\section{(iii)Accupal:}

Dr. Michael Zweifler, a dentist of Arkansas invented this device, launched in market in 2008. The mode of action of this instrument is similar to other vibratory instruments described above, the only difference being circular working tip. During injection the needle is inserted through the circular tip of the device into the tissues.

\section{Reversal of Anaesthesia:}

An ideal anaesthetic solution should have an appropriate duration of action to perform the desired procedure. However prolonged duration of anaesthesia is undesirable and uncomfortable for the patients. Soft tissue injury, uncontrolled drooling, perception of altered facial appearance difficulty in speech/smile/drink are some of the postoperative undesirable effects of soft tissue anaesthesia. These effects are more troublesome/ disturbing in paediatric patients than in adult patients. Anaesthesia reversal agents have been developed for recovery from anaesthesia. Oraverse is a safe and FDA approved local anaesthesia reversal agent developed by Novocol Pharmaceuticals. It contains Phentolamine Mesylate, a short acting alpha-adrenergic blocker which causes vasodilatation of the endothelial smooth muscle. This results in increased clearance of local anaesthesia solution from the site of injection, decreasing its duration of action. The maximum recommended dose of OraVerse for children 6-11 years of age weighing 15 to $30 \mathrm{~kg}$ is $1 /$ 2 cartridge $(0.2 \mathrm{mg})$. The safety is OraVerse in children bel ow 6 years of age is not established and hence not recommended. Reports have shown favourable clinical use by the dentists and patient satisfaction rates are also high.3,4

\section{Articaine:}

Articaine was originally synthesized as Carticaine by $\mathrm{H}$. Rushcing in 1969. It first entered clinical practice in Germany in 1976. Recently it was 
introduced in USA in 2000, Australia in 2005 and is gaining popularity in I ndia. The name was changed to Articaine in 1984. Articaine is available as a $4 \%$ with epinephrine in concentration of $1: 1,00,000$ and $1: 2,00,000$. It is a unique amide local anaesthetic in that it contains a thiophene, instead of a benzene ring. The thiophene ring allows greater lipid solubility and potency, hence Articaine is known to possess enhanced diffusion properties and better anaesthetic efficacy. Biotransformation of Articaine occurs in liver and in plasma. Good analgesic efficacy with a lower systemic toxicity allows Articaine use in a concentration higher than other amides. It has been suggested that a palatal injection may not be necessary when Articaine is delivered in a buccal infiltration. Lima - J unior et al reported that most impacted third molar extractions with Articainecan be performed without palatal anaesthesia. ${ }^{5}$ In terms of safety, Articaine is one of the safer local anaesthetic due to its rapid metabolism even when repeatedly administered. Considering the clinical efficacy and safety of Articaine, its use in paediatric dental practice can be a good alternative to other conventionally used local anaesthetic agents.

\section{Nasal Spray for Maxillary Anaesthesia:}

This is a novel technique of anaesthetizing maxillary teeth by dispensing anaesthetic solution through the nostrils using a metered device. This was an accidental discovery when a dentist, Dr. Mark Kollar took nasal spray of tetracaine for straightening his nose following an injury. He noticed his upper teeth were numb and this inspired him for further research in nasal spray for maxillary anaesthesia. A study published May 20, 2013 in the J ournal of Dental Research indicates that the experimental nasal spray may be equally effective in anesthesia within the jaw as the conventional injections with lidocaine. ${ }^{6}$ Spray which had been developed by St. Renatus of Fort Collins, Colorado has passed the third phase of the research, giving hope to obtain the approval of the FDA very soon. Its unique composition was inspired by a mixture of tetracaine hydrochloride and oxymetazol ine used in otolaryngology. Along with anesthetic properties, it also reduces the risk of bleeding by constricting the blood vessels. It has been claimed that anaesthetic solution diffuses through the thin nasal walls acting on the nerves supplying the maxillary teeth. The anaesthesia solution consists of one or two agents such lidocaine, tetracaine or benzocaine with a vasoconstrictor and an appropriate carrier. The carrier may be a gel or liquid which can hold the anaesthetic solution at an appropriate viscosity, ph and absorbability.

\section{Others:}

Computer controlled local delivery of anaesthesia (CCLAD) is an emerging local anaesthesia delivery system. Single tooth anaesthesia (STA) sytem introduced in 2006 is a CCLAD with an additional featuretermed "Dynamic Pressure Sensing Technology (DPS)". This senses the pressure at the tip of the neeldle and gives a real time feedback to the practitioner enabling to inject the solution at the most appropriate tissue during intra-ligamentary injections. J et injections also termed as "Needleless" injections infuses the anaesthetic solution through the mucosa/skin when delivered at a high pressure. J et injections produce a jolt during administration making it uncomfortable for paediatric use. Intra-Osseous anaesthesia involves depositing anaesthetic sol ution into the cancellous marrow in the vicinity of the apex of the teeth. Stabident, X-Tip, Intra-Flow are popular systems for intra-osseous anaesthesia.

Research studies are presently being conducted on the various products described above to validate its efficacy. Limited accessibility and cost of these advanced products have made the practitioners to adopt conventional local anaesthesia techniques in developing countries. However, it is important for a practitioner to be familiar with developments occurring in the field of local anaesthesia. More clinical use and research using such developed products should be encouraged for a better patient care.

\section{References:}

1. Stecker SS, Swift J Q, Hodges J S, Erickson PR. Should a mucoadhesive patch (DentiPatch) be used for gingival anesthesia in children? Anesth Prog. 2002; 49(1):3-8.

2. Shahidi Bonjar AH. Syringe micro vibrator (SMV) a new device being introduced in dentistry to alleviate pain and anxiety of intraoral injections, and a comparative study with a similar device. Ann Surg Innov Res 2011; 5(1):1.

3. Saunders TR, Psaltis G, Weston J F, Y anase RR, Rogy SS, Ghalie RG. In-practice evaluation of OraVerse for the reversal of soft-tissue anesthesia after dental procedures. Compend Contin Educ Dent 2011; 32(5):58-62.

4. Yagiela J A. What's new with phentolamine mesylate: a reversal agent for local anaesthesia? SAAD Dig 2011; 27:3-7.

5. Lima J L, Dias-Ribeiro E, Ferreira-Rocha J, Soares R, Costa FWG, Fan S, et al. Comparison of buccal infiltration of $4 \%$ articaine with $1: 100,000$ and 1:200,000 epinephrine for extraction of maxillary third molars with pericoronitis: a pilot study. Anesth Prog 2013; 60(2):42-45.

6. Ciancio SG, Hutcheson MC, Ayoub F, Pantera EA, Pantera CT, Garlapo DA, et al. Safety and efficacy of a novel nasal spray for maxillary dental anesthesia. J Dent Res 2013; 92(7):43-48. 